\title{
Incorporation of viscosity scaling group into analysis of MPMS index for laboratory characterization of wettability of reservoir rocks
}

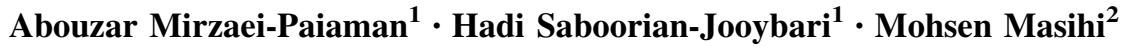

Received: 19 December 2014/ Accepted: 17 January 2016/Published online: 8 February 2016

(c) The Author(s) 2016. This article is published with open access at Springerlink.com

\begin{abstract}
Wettability is a key parameter affecting petrophysical properties of reservoir rocks. Mirzaei-Paiaman et al. (Energy Fuels 27:7360-7368, 2013) presented an index (referred to as MPMS) for laboratory characterization of wettability of native- or restored-state reservoir rock samples. To use this index two counter-current spontaneous imbibition (COUCSI) experiments are needed, one on the native- or restored-state core sample and another on the strongly water-wet (SWW) reference system. Slope analysis of recovery data in these two systems gives inputs for determination of MPMS index. The two systems must have the same pore structure, initial water saturation, and viscosity ratio. The case of high viscosity reservoir crude needs the reference COUCSI test to be performed using a high viscosity polar compounds-free oil. Such test could be very slow and time consuming. The purpose of this study is to remove the need for limiting condition of the same viscosity ratio between the two systems, so that the reference experiment could be performed using any viscosity ratio independent of viscosity ratio of the native- or restored-state system. Thus, in the case of high viscosity reservoir crude, the reference test can be conducted using a low viscosity oil. Such test is relatively very fast and time efficient. We do this by benefiting the viscosity scaling group (VSG) proposed by Mason et al. (J Pet Sci Eng 72:195-205, 2010). Using experimental data from three
\end{abstract}

Hadi Saboorian-Jooybari

hadi.saboorian@gmail.com; saboorian.h@nisoc.ir

1 Department of Petroleum Engineering, National Iranian South Oil Company (NISOC), Ahvaz, Iran

2 Department of Chemical and Petroleum Engineering, Sharif University of Technology, P.O. Box 11365-9465, Azadi Ave., Tehran, Iran sets of mixed-wet systems, we show that applicability of this VSG is not limited to SWW systems only. This VSG is used to relax the need for the limiting condition of the same viscosity ratio between the native- or restored-state and reference systems in the MPMS method. Using two sets of experimental data, we show that acceptable results are observed when comparing the MPMS indices estimated by the proposed technique and the original MPMS method.

Keywords Spontaneous imbibition - Wettability index · MPMS $\cdot$ Viscosity ratio $\cdot$ Scaling group

\section{Introduction}

Wettability is a key parameter affecting petrophysical properties of reservoir rocks and is defined as preference of a solid to be in contact with one fluid rather than another. The best results when studying the wetting characteristics of reservoir rocks are obtained by conducting laboratory experiments on native-state core samples. These core samples are obtained and stored by methods that preserve the wettability of reservoir. In some cases the native wettability is restored by flooding and aging processes. The core is first cleaned and then saturated with original or synthetic formation brine, followed by injection of reservoir crude oil. Finally, the core sample is aged at reservoir temperature for appropriate time.

Several quantitative methods have been proposed to characterize wettability of native- or restored-state rocks in laboratory. These methods describe wettability in terms of numbers for the purpose of comparison between different systems. These methods include contact angle (Adamson 1982), Amott (Amott 1959), Amott-Harvey (Boneau and Clampitt 1977; Trantham and Clampitt 1977), USBM 
(Donaldson et al. 1969), combined Amott/USBM (Sharma and Wunderlich 1985), relative imbibition rate (Denekas et al. 1959), total capillary pressure curves (Longeron et al. 1995), relative pseudo work of imbibition (Ma et al. 1999), modified Amott (Zhou et al. 2000), NMR relaxometry (Fleury and Deflandre 2003), chemical adsorption (Strand et al. 2006) and the recent method by Mirzaei-Paiaman et al. (2013) (in this study referred to as MPMS, after the initials in their last names).

The MPMS method, based on mathematical and physical backgrounds, uses slope analysis of counter-current spontaneous imbibition (COUCSI) recovery data. The benefits of the MPMS when compared to other existing methods are: (1) it is a better measure of the spontaneous imbibition potential of rock (since the magnitude is directly proportional to the imbibition rate), (2) there is no need for forced displacement data, (3) there is no need for waiting until the COUCSI process ceases completely, and (4) the data needed to run the new method are all easy to measure.

To use the MPMS index two COUCSI experiments are needed, one on the native- or restored-state core sample and another on the strongly water-wet (SWW) reference system (i.e., the core is cleaned to become SWW and then saturated by fluids that do not alter the wetting condition). The slope analysis of recovery data in these two systems gives inputs for determination of MPMS index. As essential conditions, the SWW reference system must have the same pore structure, initial water saturation, and viscosity ratio (defined as the ratio of nonwetting phase viscosity to wetting phase viscosity) as the native- or restored-state system. Due to these conditions, the case of high viscosity reservoir crude implies that the reference COUCSI test must be performed using a high viscosity polar compounds-free oil. Such test could be very slow and time consuming. The purpose of this study is to remove the need for the limiting condition of the same viscosity ratio between the native- or restored-state and SWW reference systems. By removing this condition the reference COUCSI experiment can be performed using any viscosity ratio independent of viscosity ratio of the native- or restored-state system. So that in the case of high viscosity reservoir crude, the reference test can be conducted using a low viscosity oil. Such test is relatively very fast and time efficient.

\section{The MPMS method (background and formulations)}

For one-dimensional isothermal immiscible flow of two incompressible fluids in a porous medium neglecting gravity effects (Mirzaei-Paiaman et al. 2011a) as well as non-equilibrium effects (Schmid and Geiger 2012, 2013;
Mirzaei-Paiaman et al. 2011b; Mirzaei-Paiaman and Masihi 2014) with only one face open to flow (i.e., countercurrent flow) the governing equation, which is a highly non-linear parabolic partial differential equation of second order, appears by combining Darcy's law for wetting and nonwetting phases with the capillary pressure definition and the mass continuity equation for the wetting phase. By imposing a specific inlet boundary condition, McWhorter and Sunada (1990) presented an exact analytical solution to this governing equation for the situation where the entering fluid has not reached the no-flow boundary. Schmid et al. (2011) noticed that the imposed boundary condition used by McWhorter and Sunada (1990) to solve the problem is redundant for the typical COUCSI experiments and the solution describes this process. Schmid and Geiger (2012, 2013) and Mirzaei-Paiaman and Masihi (2013) used this solution to derive universal scaling equations for recovery by COUCSI. Mirzaei-Paiaman et al. (2013) used the subject solution and scaling concepts to present MPMS index for characterizing wettability of rocks.

Using the subject solution for the COUCSI process, Mirzaei-Paiaman et al. (2013) arrived at the following equation:

$\frac{Q}{V_{\mathrm{P}}}=X \sqrt{\frac{2 \sigma \sqrt{\frac{k_{c}}{\phi}}}{\mu_{\mathrm{nw}} L_{c}^{2}}} t^{1 / 2}$

in which,

$X=\sqrt{\int_{S_{w i}}^{S_{w, \mathrm{BC}}} \frac{\left(S_{\mathrm{wi}}-S_{\mathrm{w}}\right) \frac{k_{\mathrm{rw}} k_{\mathrm{rnw}} \cos (\theta)}{k_{\mathrm{rw}}+k_{\mathrm{rnw}} \frac{\mu_{\mathrm{w}}}{\mu_{\mathrm{nw}}}} \frac{d J}{d S_{\mathrm{w}}}}{F\left(S_{w}\right)} d S_{\mathrm{w}}}$

In these equations $Q$ is the cumulative volumetric recovery at any time $(t), V_{\mathrm{P}}$ is the pore volume of rock, $\sigma$ is the interfacial tension between the wetting and nonwetting phases, $k_{\mathrm{c}}$ is the characteristic permeability by MirzaeiPaiaman and Masihi (2013) to account for directional permeability defined in Eq. 3, $\phi$ is the porosity, $\mu_{\mathrm{nw}}$ is the dynamic viscosity of the nonwetting phase, $L_{\mathrm{c}}$ is the characteristic length by Ma et al. (1995) to compensate different sample shape, size, and boundary conditions defined in Eq. 4, $S_{\mathrm{w}}$ is the wetting phase saturation, $S_{\mathrm{wi}}$ is the initial wetting phase saturation, $S_{\mathrm{w}, \mathrm{BC}}$ is the wetting phase saturation at open boundary, $k_{\mathrm{rw}}$ is the relative permeability of the wetting phase, $k_{\text {rnw }}$ is the relative permeability of the nonwetting phase, $\theta$ is the contact angle, $J$ is the Leverett dimensionless capillary pressure (Leverett 1941) and $F$ is the fractional flow function with capillary pressure included defined in Eq. 5.

$k_{c}=\left(\prod_{j=1}^{n} k_{j}\right)^{1 / n}$ 
in which $n$ is the total number of flow directions.

$L_{c}=\sqrt{\frac{V_{\mathrm{ma}}}{\sum_{i=1}^{s} \frac{A_{\mathrm{ma}, \mathrm{i}}}{l_{\mathrm{ma}, \mathrm{i}}}}}$

where $s$ is the number of the open faces to imbibition, $V_{\mathrm{ma}}$ is the matrix bulk volume, $A_{\mathrm{ma}}$ is the surface area open to flow in a given flow direction, and $l_{\mathrm{ma}}$ the distance from the open surface to the corresponding no-flow boundary.

$F\left(S_{w}\right)=1-\frac{\int_{S_{\mathrm{w}}}^{S_{\mathrm{w}, \mathrm{BC}}} \frac{\left(\beta-S_{\mathrm{w}}\right) D(\beta)}{F(\beta)} d \beta}{\int_{S_{\mathrm{wi}}}^{S_{\mathrm{w}}\left(\frac{\left(S_{\mathrm{w}}-S_{\mathrm{wi}}\right) D\left(S_{\mathrm{w}}\right)}{F\left(S_{\mathrm{w}}\right)} d S_{\mathrm{w}}\right.}}$

in which $D\left(S_{\mathrm{w}}\right)$ is the capillary diffusion function defined as (McWhorter and Sunada 1990):

$D\left(S_{\mathrm{w}}\right)=-f\left(S_{\mathrm{w}}\right) k \frac{k_{\mathrm{rnw}}}{\mu_{\mathrm{nw}}} \frac{d P_{\mathrm{c}}}{d S_{\mathrm{w}}}$

where $P_{\mathrm{c}}$ is the capillary pressure and $f\left(S_{\mathrm{w}}\right)$ is the fractional flow function defined as (McWhorter and Sunada 1990):

$f\left(S_{\mathrm{w}}\right)=\frac{k_{\mathrm{rw}} \mu_{\mathrm{nw}}}{k_{\mathrm{rw}} \mu_{\mathrm{nw}}+k_{\mathrm{rnw}} \mu_{\mathrm{w}}}$

Mirzaei-Paiaman et al. (2013) investigated the group of variables on the right hand side of Eq. 2 and discussed that this group is a function of initial water saturation, pore structure, viscosity ratio $\left(\frac{\mu_{\mathrm{nw}}}{\mu_{\mathrm{w}}}\right)$, and wettability of the system. Wettability itself is controlled by ion composition and salinity of the wetting phase, composition of the nonwetting phase, surface charges of minerals, pore structure, and temperature. Hence, based on Eq. 1 plotting $\frac{Q}{V_{\mathrm{P}}}$ versus $\sqrt{\frac{2 \sigma \sqrt{\frac{\mathrm{c}_{\mathrm{c}}}{\phi}}}{\mu_{\mathrm{nw}} L_{\mathrm{c}}^{2}}} t^{1 / 2}$ results in a straight line from which the slope $X$ is a function of initial water saturation, pore structure, viscosity ratio, and wettability. Mirzaei-Paiaman et al. (2013) defined the MPMS index to water $Z_{\mathrm{w}}$ as:

$Z_{w}=\sqrt{\frac{X}{X_{r e f}}}$

where $X_{\text {ref }}$ is a reference slope for a cleaned and SWW system with the same pore structure, initial water saturation, and viscosity ratio as the native- or restored-state sample. This index varies from zero for strongly oil wet to unity for strongly water wet systems.

\section{Analysis}

On the basis of Eq. 1, it is expected that for the systems having the same initial water saturation, wettability, pore structure, and viscosity ratio, the curves of $\frac{Q}{V_{\mathrm{P}}}$ data versus $\sqrt{\frac{2 \sigma \sqrt{\frac{k_{c}}{\phi}}}{\mu_{\mathrm{nw}} L_{c}^{2}}} t^{1 / 2}$ collapse into a single curve. In this work, our idea is to substitute the term $\mu_{\mathrm{nw}}$ in $\sqrt{\frac{2 \sigma \sqrt{\frac{k_{\mathrm{c}}}{\phi}}}{\mu_{\mathrm{nn}}^{2} L_{\mathrm{c}}^{2}}} t^{1 / 2}$ with an appropriate viscosity scaling group VSG (herein named $\mu^{*}$ ) such that for the systems with the same initial water saturation, wettability, and pore structure but with different viscosity ratios, the curves of $\frac{Q}{V_{\mathrm{P}}}$ data versus $\sqrt{\frac{2 \sigma \sqrt{\frac{k_{\mathrm{c}}}{\phi}}}{\mu^{*} L_{\mathrm{c}}^{2}}} t^{1 / 2}$ superimpose. In fact, the aim of this work is to empirically ruling out the viscosity ratio dependence in the groups $X$ and $X_{\text {ref }}$ and bringing this effect out of the groups. The same problem has been addressed and resolved in the works studying the scaling of COUCSI recovery data.

Several equations have been proposed for scaling COUCSI recovery data. Recovery data of different systems when plotted versus an appropriate scaling equation should collapse into a single curve. Recently, Mirzaei-Paiaman and Masihi (2013) developed universal and consistent scaling equations for COUCSI experiments incorporating all the factors influencing the process. However, for the purpose of this study we investigate simpler scaling equations published before these authors. The first scaling group, suffering from many restrictions, was presented by Mattax and Kyte (1962) as:

$t_{\mathrm{D}}=\frac{\sigma \sqrt{\frac{k}{\phi}}}{\mu_{\mathrm{w}} L^{2}} t$

in which $t_{\mathrm{D}}$ is the dimensionless time. Several scaling equations have been presented to remove some of the restrictive assumptions made by Mattax and Kyte (1962) (for recent reviews see Schmid and Geiger (2012, 2013) and Mirzaei-Paiaman and Masihi (2013)). For the scaling equations developed by modifying the scaling equation of Mattax and Kyte (1962), one of the areas frequently addressed has been the way that they accounted for the effect of different viscosities in the scaling equations by replacing the term $\mu_{\mathrm{w}}$ in Eq. 9 with appropriate VSGs. Table 1 summarizes different forms of the viscosity term used in the literature.

Lucas (1918), Gupta and Civan (1994), Behbahani and Blunt (2005), and Saboorian-Jooybari and Khademi (2014) used the wetting phase viscosity term in their equations and presented scaling groups similar to that of Mattax and Kyte (1962), whereas Iffly et al. (1972), Cuiec et al. (1994), Babadagli (1996), and Tavassoli et al. (2005) used the nonwetting instead of the wetting phase viscosity. Ma et al. (1997) experimentally observed that the imbibition time was proportional to the geometrical mean of wetting and nonwetting phase viscosities. Thus, to account for the effect of fluid viscosities in the scaling equations, they used 
Table 1 Summary of different combinations of wetting and nonwetting phase viscosities used in literature works to scale COUCSI recovery curves

\begin{tabular}{|c|c|c|}
\hline Reference & VSG & Definitions \\
\hline $\begin{array}{l}\text { Lucas (1918), Mattax and Kyte (1962), Gupta and Civan (1994), Behbahani and Blunt } \\
\text { (2005), and Saboorian-Jooybari and Khademi (2014) }\end{array}$ & $\mu_{\mathrm{w}}$ & - \\
\hline Iffly et al. (1972), Cuiec et al. (1994), Babadagli (1996), and Tavassoli et al. (2005) & $\mu_{\mathrm{nw}}$ & - \\
\hline Ma et al. (1997) & $\sqrt{\mu_{\mathrm{w}} \mu_{\mathrm{nw}}}$ & - \\
\hline Wang (1999) & $\sqrt{\mu_{\mathrm{w}}^{0.75} \mu_{\mathrm{nw}}^{0.25}}$ & - \\
\hline Standnes (2009) & $\sqrt{\mu_{\mathrm{w}}^{\mathrm{VE}} \mu_{\mathrm{nw}}^{1-\mathrm{VE}}}$ & $\begin{array}{l}\mathrm{VE} \text { is an } \\
\text { adjustable parameter }\end{array}$ \\
\hline Ruth et al. (2004) & $C_{1}\left(1+C_{2}\left(\frac{\mu_{\mathrm{nw}}}{\mu_{\mathrm{w}}}\right)^{1 / \mathrm{m}}\right)^{-\mathrm{m}}$ & $\begin{array}{l}C_{1}, C_{2}, \text { and } m \text { are } \\
\quad \text { matching parameters }\end{array}$ \\
\hline Fischer et al. (2008) & $\frac{a b}{\mu_{\mathrm{w}}+b^{2} \mu_{\mathrm{nw}}}$ & $\begin{array}{l}a \text { and } b \text { are matching } \\
\text { parameters }\end{array}$ \\
\hline Mason et al. (2010) & $\mu_{\mathrm{w}}+\sqrt{\mu_{\mathrm{w}} \mu_{\mathrm{nw}}}$ & - \\
\hline
\end{tabular}

Table 2 Summary of data for the SWW COUCSI experiments performed by Fischer and Morrow (2006)

\begin{tabular}{|c|c|c|c|c|c|c|c|}
\hline Sample ID & $L_{c}, \mathrm{~m}$ & $k, \mathrm{~m}^{2}$ & $\phi$, fraction & $\sigma, \mathrm{N} / \mathrm{m}$ & $\mu_{\mathrm{w}}$, Pa.s & $\mu_{\mathrm{nw}}$, Pa.s & Viscosity ratio $\left(\frac{\mu_{\mathrm{nw}}}{\mu_{\mathrm{w}}}\right)$ \\
\hline C3-1 & 0.013 & $6.35 \mathrm{E}-14$ & 0.17 & 0.0489 & 0.0011 & 0.004 & 3.636 \\
\hline C1-1 & 0.012 & $6.23 \mathrm{E}-14$ & 0.17 & 0.0398 & 0.0044 & 0.0039 & 0.886 \\
\hline C3-9 & 0.012 & $7.05 \mathrm{E}-14$ & 0.17 & 0.0376 & 0.0087 & 0.004 & 0.460 \\
\hline C1-2 & 0.012 & $6.45 \mathrm{E}-14$ & 0.17 & 0.0353 & 0.0152 & 0.004 & 0.263 \\
\hline C3-6 & 0.012 & $6.67 \mathrm{E}-14$ & 0.17 & 0.0344 & 0.0218 & 0.004 & 0.183 \\
\hline C3-8 & 0.012 & $6.27 \mathrm{E}-14$ & 0.17 & 0.0329 & 0.0395 & 0.004 & 0.101 \\
\hline C3-7 & 0.012 & $6.45 \mathrm{E}-14$ & 0.17 & 0.0321 & 0.0594 & 0.004 & 0.067 \\
\hline C1-3 & 0.012 & $6.27 \mathrm{E}-14$ & 0.17 & 0.0312 & 0.0998 & 0.004 & 0.040 \\
\hline C1-16 & 0.012 & $6.99 \mathrm{E}-14$ & 0.17 & 0.0306 & 0.185 & 0.004 & 0.022 \\
\hline C1-20 & 0.012 & $7.12 \mathrm{E}-14$ & 0.17 & 0.0283 & 0.8269 & 0.004 & 0.005 \\
\hline C1-25 & 0.012 & $7.15 \mathrm{E}-14$ & 0.17 & 0.0277 & 1.6466 & 0.004 & 0.002 \\
\hline C1-7 & 0.012 & $6.51 \mathrm{E}-14$ & 0.17 & 0.0524 & 0.0011 & 0.022 & 20.000 \\
\hline C1-9 & 0.012 & $6.54 \mathrm{E}-14$ & 0.17 & 0.0412 & 0.0044 & 0.022 & 5.000 \\
\hline C1-10 & 0.012 & $6.88 \mathrm{E}-14$ & 0.17 & 0.0373 & 0.0087 & 0.022 & 2.529 \\
\hline C1-8 & 0.012 & $6.97 \mathrm{E}-14$ & 0.17 & 0.0359 & 0.0152 & 0.022 & 1.447 \\
\hline C1-6 & 0.012 & $6.55 \mathrm{E}-14$ & 0.17 & 0.0345 & 0.022 & 0.022 & 1.000 \\
\hline C1-4 & 0.012 & $6.61 \mathrm{E}-14$ & 0.17 & 0.0331 & 0.0396 & 0.022 & 0.556 \\
\hline C1-5 & 0.012 & $6.80 \mathrm{E}-14$ & 0.17 & 0.0325 & 0.0966 & 0.022 & 0.228 \\
\hline C1-22 & 0.012 & $6.97 \mathrm{E}-14$ & 0.16 & 0.0308 & 0.2284 & 0.022 & 0.096 \\
\hline C5-19 & 0.012 & $8.57 \mathrm{E}-14$ & 0.18 & 0.0295 & 0.5227 & 0.022 & 0.042 \\
\hline C1-26 & 0.012 & $6.78 \mathrm{E}-14$ & 0.17 & 0.0286 & 1.6466 & 0.022 & 0.013 \\
\hline C1-11 & 0.012 & $6.87 \mathrm{E}-14$ & 0.17 & 0.0531 & 0.0011 & 0.043 & 39.091 \\
\hline C1-12 & 0.012 & $6.25 \mathrm{E}-14$ & 0.17 & 0.0417 & 0.0044 & 0.043 & 9.773 \\
\hline C1-13 & 0.012 & $5.56 \mathrm{E}-14$ & 0.17 & 0.0364 & 0.0152 & 0.043 & 2.829 \\
\hline C1-15 & 0.012 & $7.04 \mathrm{E}-14$ & 0.17 & 0.0346 & 0.0354 & 0.043 & 1.215 \\
\hline C1-14 & 0.012 & $7.00 \mathrm{E}-14$ & 0.17 & 0.0324 & 0.0966 & 0.043 & 0.445 \\
\hline C1-21 & 0.012 & $8.20 \mathrm{E}-14$ & 0.18 & 0.0319 & 0.0999 & 0.043 & 0.430 \\
\hline C1-19 & 0.012 & $6.99 \mathrm{E}-14$ & 0.17 & 0.0311 & 0.2284 & 0.043 & 0.188 \\
\hline C1-17 & 0.012 & $7.72 \mathrm{E}-14$ & 0.18 & 0.0296 & 0.5227 & 0.043 & 0.082 \\
\hline C1-18 & 0.012 & $6.74 \mathrm{E}-14$ & 0.16 & 0.0285 & 1.6466 & 0.043 & 0.026 \\
\hline
\end{tabular}


Table 3 Summary of data for the mixed-wet COUCSI experiments by Tong et al. (2002)

\begin{tabular}{lllllllll}
\hline Set no. & Sample ID & $L_{c}, \mathrm{~m}$ & $k, \mathrm{~m}^{2}$ & $\phi$, fraction & $\sigma, \mathrm{N} / \mathrm{m}$ & $\mu_{\mathrm{w}}$, Pa.s & $\mu_{o}$, Pa.s & Viscosity ratio $\left(\frac{\mu_{o}}{\mu_{\mathrm{w}}}\right)$ \\
\hline 1 & 1B13 & 0.012669 & $9.909 \mathrm{E}-14$ & 0.1851 & 0.0495 & 0.000967 & 0.0038 & 3.930 \\
1 & 1B14 & 0.012665 & $8.597 \mathrm{E}-14$ & 0.1804 & 0.0495 & 0.000967 & 0.0038 & 3.930 \\
1 & 1B21 & 0.012657 & $1.048 \mathrm{E}-13$ & 0.1843 & 0.0495 & 0.000967 & 0.0082 & 8.480 \\
1 & 1B20 & 0.012731 & $9.732 \mathrm{E}-14$ & 0.1837 & 0.0495 & 0.000967 & 0.016 & 16.546 \\
1 & 1B17 & 0.012652 & $8.557 \mathrm{E}-14$ & 0.1816 & 0.0495 & 0.000967 & 0.0367 & 37.952 \\
2 & 2B27 & 0.012646 & $1.050 \mathrm{E}-13$ & 0.1856 & 0.0495 & 0.000967 & 0.0038 & 3.930 \\
2 & 1B32 & 0.012646 & $9.880 \mathrm{E}-14$ & 0.1894 & 0.0495 & 0.000967 & 0.0084 & 8.687 \\
2 & 1B33 & 0.01267 & $9.051 \mathrm{E}-14$ & 0.187 & 0.0495 & 0.000967 & 0.018 & 18.614 \\
2 & 2B9 & 0.012684 & $8.695 \mathrm{E}-14$ & 0.1855 & 0.0495 & 0.000967 & 0.018 & 18.614 \\
2 & 2B2 & 0.012619 & $7.837 \mathrm{E}-14$ & 0.1853 & 0.0495 & 0.000967 & 0.0395 & 40.848 \\
2 & 2B18 & 0.01266 & $7.906 \mathrm{E}-14$ & 0.1849 & 0.0495 & 0.000967 & 0.066 & 68.252 \\
3 & 4B6 & 0.012663 & $8.448 \mathrm{E}-14$ & 0.181 & 0.0495 & 0.000967 & 0.0038 & 3.930 \\
3 & 4B16 & 0.012592 & $1.060 \mathrm{E}-13$ & 0.1917 & 0.0495 & 0.000967 & 0.0038 & 3.930 \\
3 & 4B5 & 0.012646 & $8.547 \mathrm{E}-14$ & 0.1811 & 0.0495 & 0.000967 & 0.018 & 18.614 \\
3 & 4B7 & 0.012665 & $8.271 \mathrm{E}-14$ & 0.1813 & 0.0495 & 0.000967 & 0.1068 & 110.445 \\
3 & 4B9 & 0.012631 & $9.988 \mathrm{E}-14$ & 0.1818 & 0.0495 & 0.000967 & 0.1068 & 110.445 \\
3 & 4B13 & 0.012609 & $9.870 \mathrm{E}-14$ & 0.1847 & 0.0495 & 0.000967 & 0.18 & 186.143 \\
\hline
\end{tabular}

Fig. 1 Curves of recovery by COUCSI experiments performed by Fischer and Morrow (2006) for SWW systems

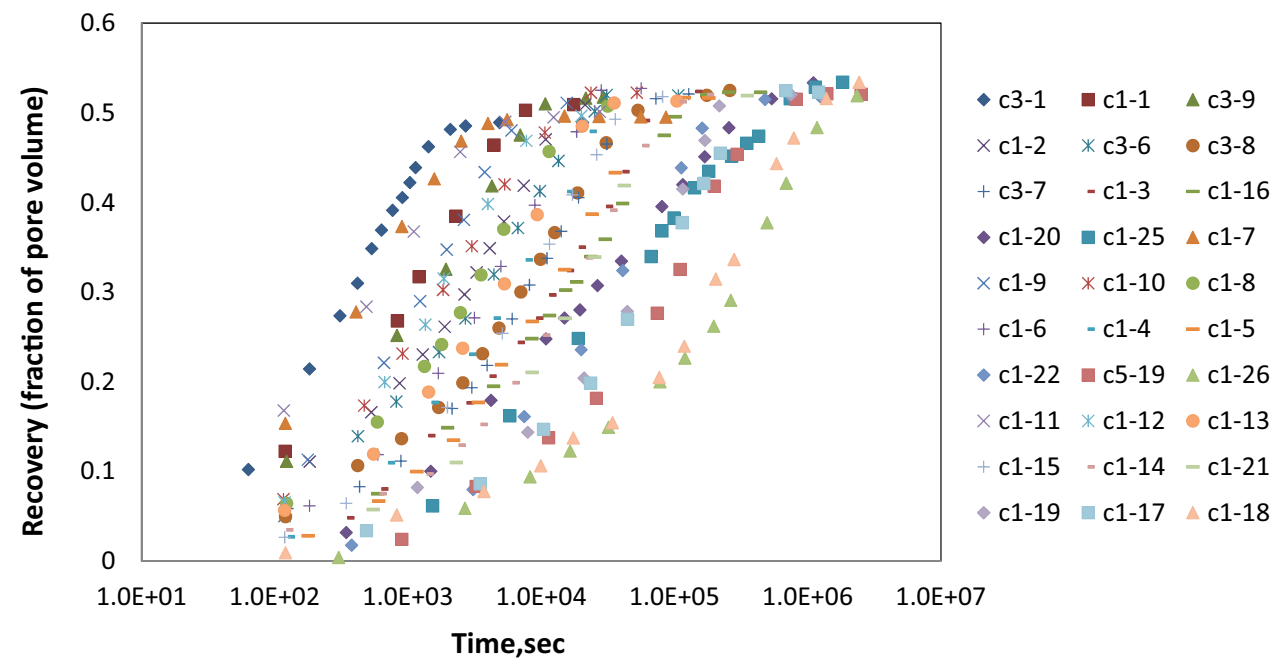

the empirical term of geometrical mean $\left(\sqrt{\mu_{\mathrm{w}} \mu_{\mathrm{nw}}}\right)$ instead of the wetting phase viscosity in Eq. 9. Wang (1999) proposed another form of VSG. However, use of this form and also the geometric mean of Ma et al. (1997) do not respond when viscosity of the nonwetting phase becomes relatively small (as with air, or with a highly viscous wetting phase, for example) (Fischer et al. 2008; Mason et al. 2010). The VSGs by Standnes (2009), Fischer et al. (2008), and Ruth et al. (2004) suffer from having fitting parameters that make their routine application difficult. To resolve these problems, Mason et al. (2010) empirically proposed using $\mu_{\mathrm{w}}+\sqrt{\mu_{\mathrm{w}} \mu_{\mathrm{nw}}}$ as an appropriate VSG. This VSG, which causes the scaling equation of Mason et al. (2010) to have the form of the following equation, gave close correlation of data for four orders of magnitude variation in viscosity ratio for the SWW systems having the same initial water saturation, pore structure, and boundary condition.

$t_{\mathrm{D}}=\frac{2 \sigma \sqrt{\frac{k}{\phi}}}{\left(\mu_{\mathrm{w}}+\sqrt{\mu_{\mathrm{w}} \mu_{\mathrm{nw}}}\right) L_{\mathrm{c}}^{2}} t$ 
Fig. 2 Curves of recovery by COUCSI experiments performed by Tong et al. (Tong et al. 2002) for mixed-wet systems, set 1 (top), set 2 (middle), and set 3 (bottom)
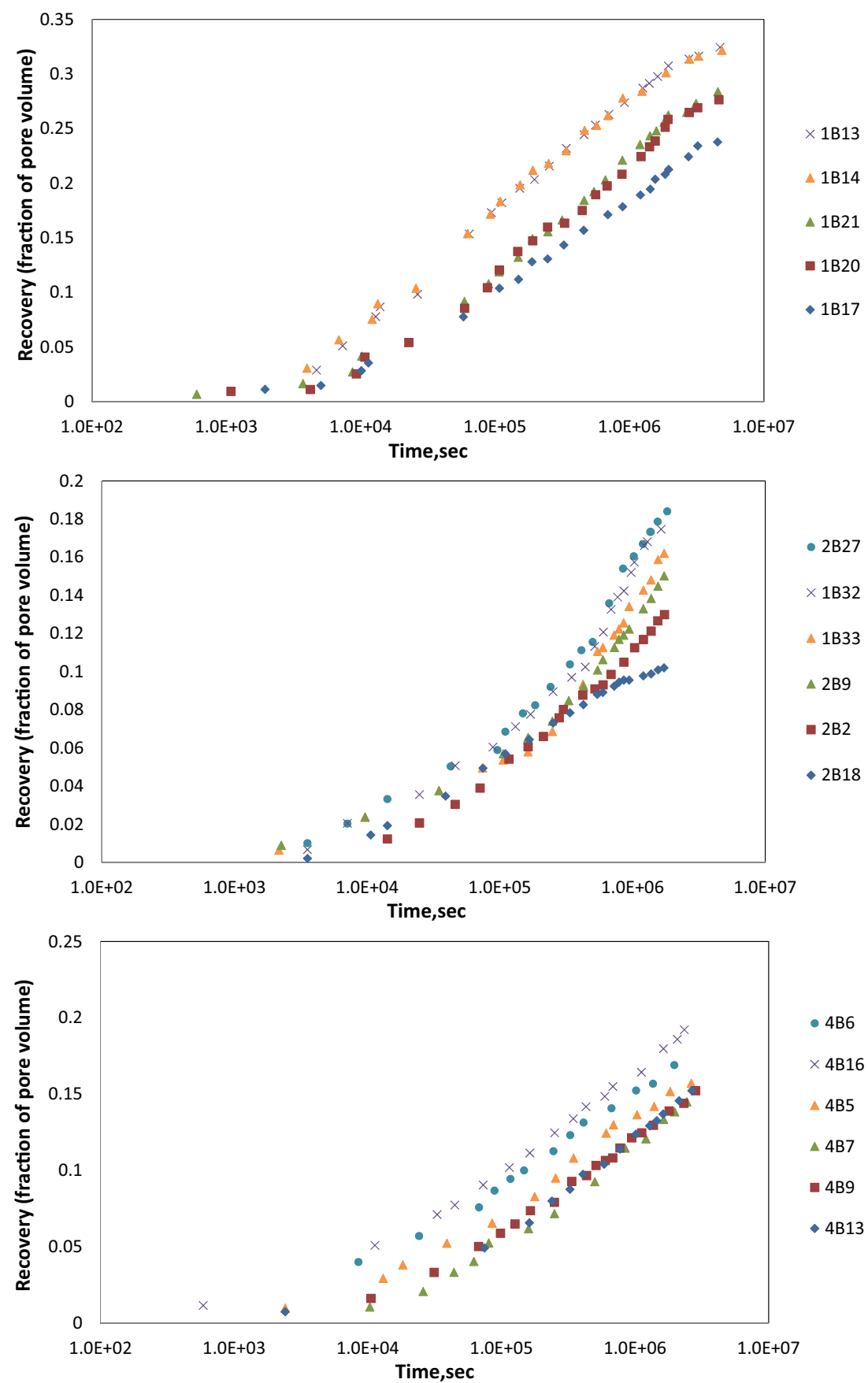

Mason et al. (2010) observed that using this VSG the shapes of the production curves showed detectable differences for the different boundary conditions. They therefore presented comparisons of the correlations for the effect of viscosity ratio separately for studied boundary conditions. Therefore, it can be concluded that if using the VSG $\mu_{\mathrm{w}}+\sqrt{\mu_{\mathrm{w}} \mu_{\mathrm{nw}}}$, the traditional characteristic length definition cannot compensate for different sample size, shape, and boundary conditions. Although Mason et al. (2010) proposed their empirical VSG for SWW systems, in the next section using published experimental data from three sets of mixedwet systems (the common wettability state for most porous media undergoing the wettability test), we show that applicability of this VSG is not limited to SWW systems only. In other words, the objective VSG has ability to scale COUCSI recovery data regardless of their wettability state.

A simple comparison between the scaling equation of Mason et al. (2010) and the group of variables on the right hand side of Eq. 1 (excluding the term $X$ ) reveals that the objective VSG $\mu^{*}$ can be chosen as $\mu_{\mathrm{w}}+\sqrt{\mu_{\mathrm{w}} \mu_{\mathrm{nw}}}$. This 
Fig. 3 Curves of recovery in terms of pore volume versus the scaling group of

$\sqrt{\frac{2 \sigma \sqrt{\frac{k_{c}}{\phi}}}{\left(\mu_{\mathrm{w}}+\sqrt{\mu_{\mathrm{w}} \mu_{\mathrm{nw}}}\right) L_{c}^{2}}} t$ for the SWW data of Fig. 1

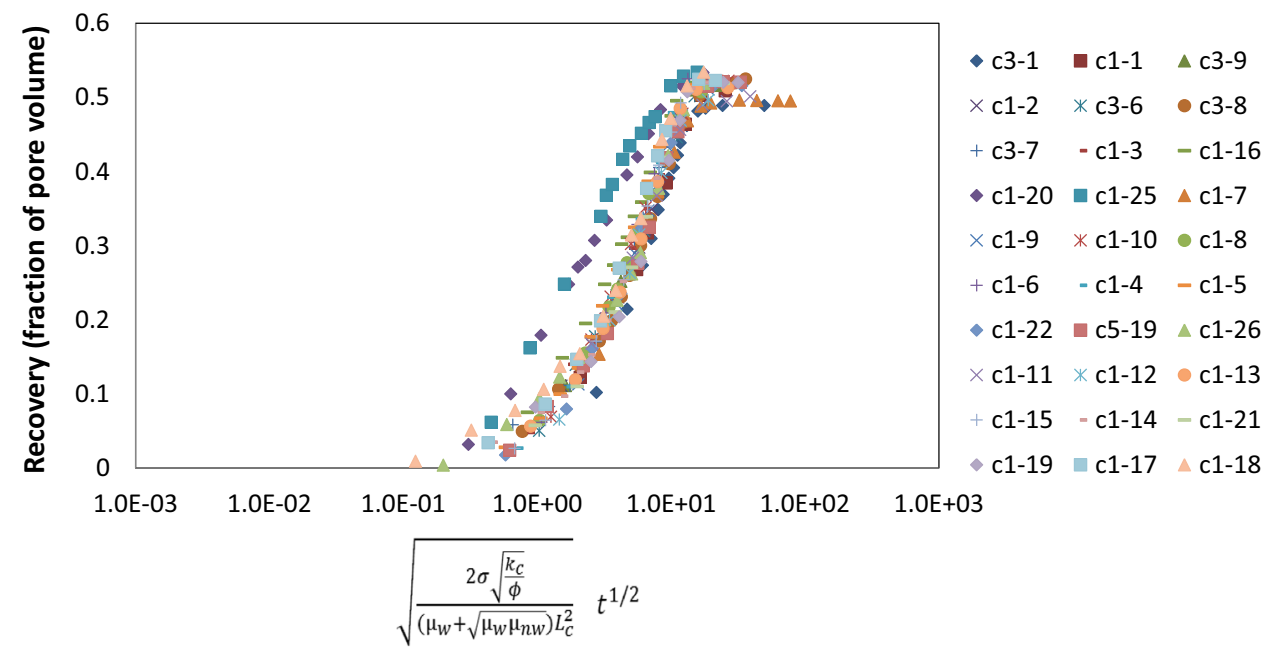

substitution will relax the constraint of the same viscosity ratio between the two COUCSI tests on the original and reference systems. Therefore, it is expected that when using MPMS index for the two systems, one can plot $\frac{Q}{V_{\mathrm{P}}}$ data versus $\sqrt{\frac{2 \sigma \sqrt{\frac{k_{\mathrm{c}}}{\phi}}}{\left(\mu_{\mathrm{w}}+\sqrt{\left.\mu_{\mathrm{w}} \mu_{\mathrm{nw}}\right)} L_{\mathrm{c}}\right.}} t^{1 / 2}$ instead of $\sqrt{\frac{2 \sigma \sqrt{\frac{\mathrm{k}_{\mathrm{c}}}{\phi}}}{\mu_{\mathrm{nw}} L_{\mathrm{c}}^{2}}} t^{1 / 2}$ to obtain the slopes $X$ and $X_{\text {ref }}$. In this case the only essential condition would be the same initial water saturation, pore structure, and boundary condition between the original and reference porous systems. The condition of the similar boundary condition between the two systems is not restrictive at all because imbibition tests to evaluate wettability are normally performed using the all faces open (AFO) configuration as the only boundary condition. In the next section, we will show that the MPMS indices estimated by the proposed method (i.e., using the concept of VSG) are in good agreement with the original MPMS indices. Indeed, in this work for the first time we present another application of VSGs, as their application has been traditionally limited to scaling studies.

\section{Validation}

\section{Validation of ability of the VSG $\mu_{\mathrm{w}}+\sqrt{\mu_{\mathrm{w}} \mu_{\mathrm{nw}}}$ for scaling}

In this section, it is intended to show the acceptable scaling performance of the VSG $\mu_{w}+\sqrt{\mu_{w} \mu_{n w}}$ for a wide range of wetting and nonwetting phase viscosities using the published SWW and mixed-wet experimental data of, respectively, Fischer and Morrow (2006) and Tong et al. (2002). Fischer and Morrow (2006) performed COUCSI experiments using the cylindrical SWW oil saturated Berea sandstones with zero initial water saturation. They used glycerol as the viscosifying agent to vary the wetting phase viscosity. In terms of viscosity ratio, the reported experiments cover the wide range $0.002<\mu_{\mathrm{nw}} / \mu_{\mathrm{w}}<39.091$. The boundary condition for all the experiments was AFO. Between the samples all parameters except the viscosity ratio are the same. Tong et al. (2002) performed three sets of COUCSI experiments using the cylindrical mixed-wet Berea sandstones. There exists different extents of mixed wettability among the individual sets. This difference in wettability among individual sets was established by choosing different aging temperatures and pore volumes of Decalin to displace the asphaltinic crude. In set 1, 2, and 3 the aging temperature and pore volumes of injected Decalin were, respectively, $75^{\circ} \mathrm{C}$ and $20,95^{\circ} \mathrm{C}$ and 5 , and $75^{\circ} \mathrm{C}$ and 5. In their imbibition experiments, mineral oils with different viscosities were prepared by mixing Soltrol 220 mineral oil $(3.8 \mathrm{cp})$ and white mineral oil $(180.0 \mathrm{cp})$ in various ratios. Between the samples in each set, all parameters except the viscosity ratio are the same (in each close). In terms of viscosity ratio, the reported experiments in sets 1, 2, and 3 cover the range, respectively, $3.930<\mu_{\mathrm{nw}} / \mu_{\mathrm{w}}<37.952,3.930<\mu_{\mathrm{nw}} / \mu_{\mathrm{w}}<68.252$, and $3.930<\mu_{\mathrm{nw}} / \mu_{\mathrm{w}}<186.143$. The boundary condition for all of the experiments was AFO. In all the experiments studied in this work permeability only in one direction was reported. Therefore, we assume the same permeability in all directions making the characteristic permeability (Mirzaei-Paiaman and Masihi 2013) the same as the singledirection reported permeability. This is a reasonable assumption for the homogenous and isotropic Berea sandstones. All relevant rock and fluid properties of these experiments are summarized in Tables 2 and 3. The recovery curves versus time of all experiments are shown in Figs. 1 and 2 for, respectively, SWW and mixed-wet systems. set the numeral values of initial water saturation are very 
Fig. 4 Curves of recovery in terms of pore volume versus the scaling group of

$\sqrt{\frac{2 \sigma \sqrt{\frac{k_{c}}{\phi}}}{\left(\mu_{\mathrm{w}}+\sqrt{\mu_{\mathrm{w}} \mu_{\mathrm{nw}}}\right) L_{c}^{2}}} t$ for the mixedwet data of Fig. 2, set 1 (top), set 2 (middle), and set 3 (bottom)
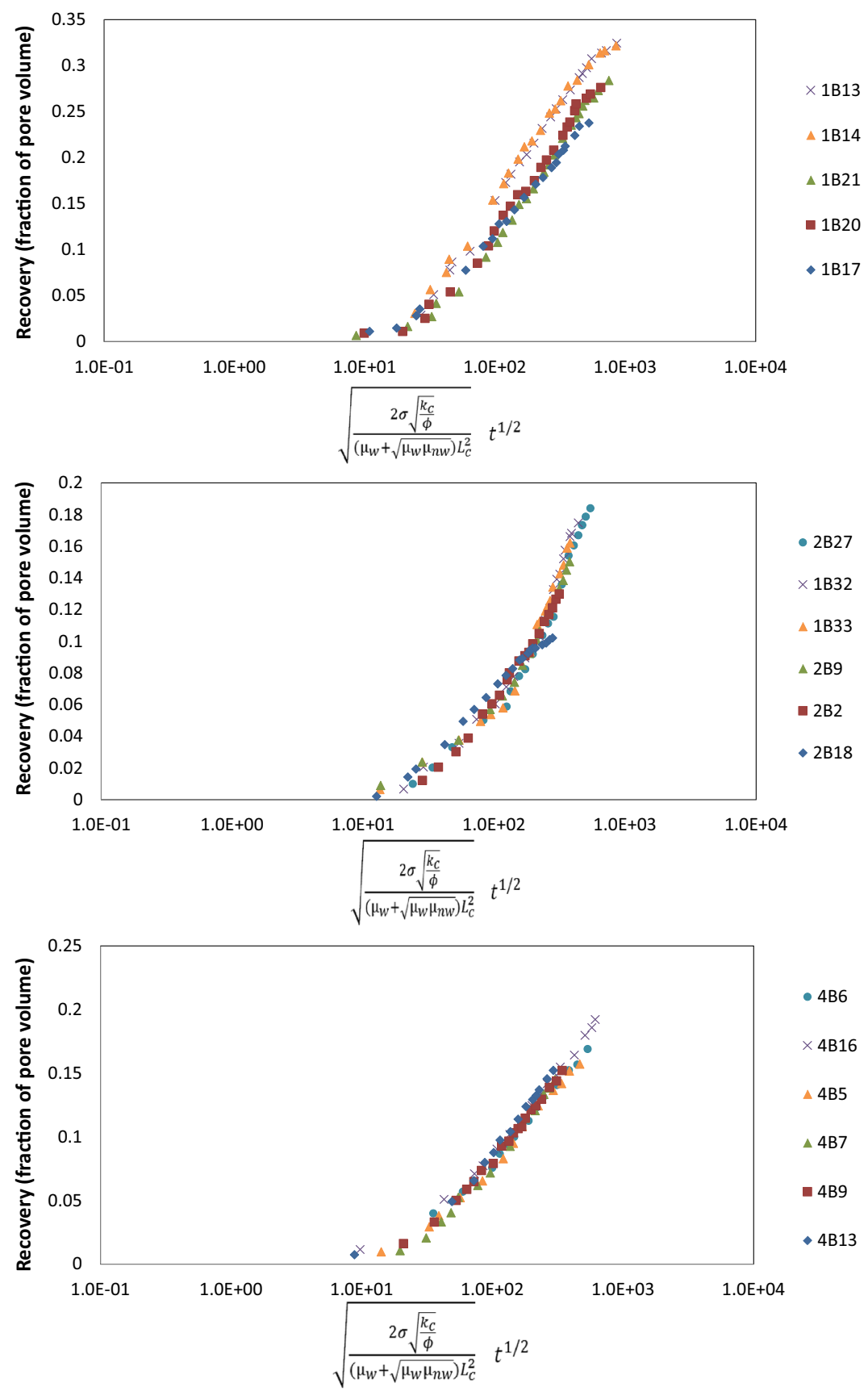

The scaling group $\sqrt{\frac{2 \sigma \sqrt{\frac{\mathrm{k}_{\mathrm{c}}}{\phi}}}{\left(\mu_{\mathrm{w}}+\sqrt{\mu_{\mathrm{w}} \mu_{\mathrm{nw}}}\right) L_{\mathrm{c}}^{2}}} t^{1 / 2}$ was used to scale data of the experiments (Figs. 3, 4). We should note that for the purpose of comparison, Figs. 1 and 3 do have the same number of logarithmic cycles, 6 numbers, on their horizontal axes. This number is 5 for Figs. 2 and 4 . As can be clearly seen in Figs. 3 and 4, this group shows a very good scaling performance. However, in Fig. 3 the experiments C1-20 and C1-
25 are exceptions. Investigation of viscosity ratio of these two experiments, which lie to the left of the other superimposed curves, reveals that viscosity ratios of them are extremely low (i.e., 0.005 and 0.002 ). In fact, this scaling group becomes inaccurate as the viscosity ratio is substantially reduced. However, we should note that the departure from the universal curve occurs for values of the viscosity ratio less than 0.005 , which are not of practical interest and importance. 
Table 4 Summary of data for the COUCSI experiments performed by Zhou et al. (2000)

\begin{tabular}{lllllllllll}
\hline Sample ID & $L_{c}, \mathrm{~m}$ & $k, \mathrm{~m}^{2}$ & $\phi$, fraction & $\sigma, \mathrm{N} / \mathrm{m}$ & $\mu_{w}$, Pa.s & $\mu_{n w}$, Pa.s & $X$ & $R^{2}$ & $Z_{\mathrm{w}}$ by MPMS & $Z_{w}$ estimated by the proposed method \\
\hline Al:0 h & 0.013 & $3.60 \mathrm{E}-13$ & 0.217 & 0.0242 & 0.000967 & 0.03925 & 0.015 & 0.998 & 1.00 & 0.89 \\
Al:4 h & 0.013 & $3.55 \mathrm{E}-13$ & 0.215 & 0.0242 & 0.000967 & 0.03925 & 0.00367 & 0.996 & 0.50 & 0.44 \\
Al:48 h & 0.013 & $3.65 \mathrm{E}-13$ & 0.214 & 0.0242 & 0.000967 & 0.03925 & 0.00234 & 0.988 & 0.37 & 0.35 \\
Al:72 h & 0.013 & $3.00 \mathrm{E}-13$ & 0.225 & 0.0242 & 0.000967 & 0.03925 & 0.00063 & 0.993 & 0.24 & 0.18 \\
Al:240 h & 0.013 & $3.64 \mathrm{E}-13$ & 0.217 & 0.0242 & 0.000967 & 0.03925 & 0.00026 & 0.988 & 0.17 & 0.12 \\
Ak:0 h & 0.013 & $3.65 \mathrm{E}-13$ & 0.223 & 0.0242 & 0.000967 & 0.03925 & 0.02109 & 0.983 & 1.00 & 0.96 \\
Ak:1 h & 0.013 & $3.63 \mathrm{E}-13$ & 0.220 & 0.0242 & 0.000967 & 0.03925 & 0.01485 & 0.981 & 0.83 & 0.81 \\
Ak:4 h & 0.013 & $3.60 \mathrm{E}-13$ & 0.226 & 0.0242 & 0.000967 & 0.03925 & 0.00544 & 0.99 & 0.52 & 0.49 \\
Ak:6 h & 0.013 & $3.36 \mathrm{E}-13$ & 0.220 & 0.0242 & 0.000967 & 0.03925 & 0.00446 & 0.996 & 0.45 & 0.44 \\
Ak:12 h & 0.013 & $3.43 \mathrm{E}-13$ & 0.225 & 0.0242 & 0.000967 & 0.03925 & 0.00163 & 0.996 & 0.29 & 0.27 \\
Ak:24 h & 0.013 & $3.74 \mathrm{E}-13$ & 0.226 & 0.0242 & 0.000967 & 0.03925 & 0.00068 & 0.994 & 0.2 & 0.17 \\
Ak:72 h & 0.013 & $3.67 \mathrm{E}-13$ & 0.223 & 0.0242 & 0.000967 & 0.03925 & 0.0006 & 0.993 & 0.17 & 0.16 \\
Ak:240 h & 0.013 & $3.55 \mathrm{E}-13$ & 0.218 & 0.0242 & 0.000967 & 0.03925 & 0.00049 & 0.985 & 0.14 & 0.15 \\
\hline
\end{tabular}

Table 5 Summary of data for the COUCSI experiments performed by Viksund et al. (1998)

\begin{tabular}{llllllllll}
\hline Sample ID & $L_{c}, \mathrm{~m}$ & $S_{w i}$, fraction & $k, \mathrm{~m}^{2}$ & $\phi$, fraction & $\sigma, \mathrm{N} / \mathrm{m}$ & $\mu_{w}$, Pa.s & $\mu_{\text {nw }}$, Pa.s & $X_{\text {ref }}$ & $R^{2}$ \\
\hline Berea1-15 & 0.0128 & 0.148 & $9.86 \mathrm{E}-13$ & 0.228 & 0.048 & 0.000967 & 0.00143 & 0.0189 & 0.99 \\
Berea1-20\#1 & 0.0127 & 0.200 & $10.1 \mathrm{E}-13$ & 0.229 & 0.048 & 0.000967 & 0.00143 & 0.0228 & 0.99 \\
\hline
\end{tabular}

Fig. 5 Curves of recovery normalized by pore volume versus $\sqrt{\frac{2 \sigma \sqrt{\frac{k_{c}}{\phi}}}{\left(\mu_{\mathrm{w}}+\sqrt{\mu_{\mathrm{w}} \mu_{\mathrm{nw}}}\right) L_{c}^{2}}} t^{1 / 2}$ for the first set of experiments performed by Zhou et al. (2000) (with initial water saturations close to $15 \%$ )

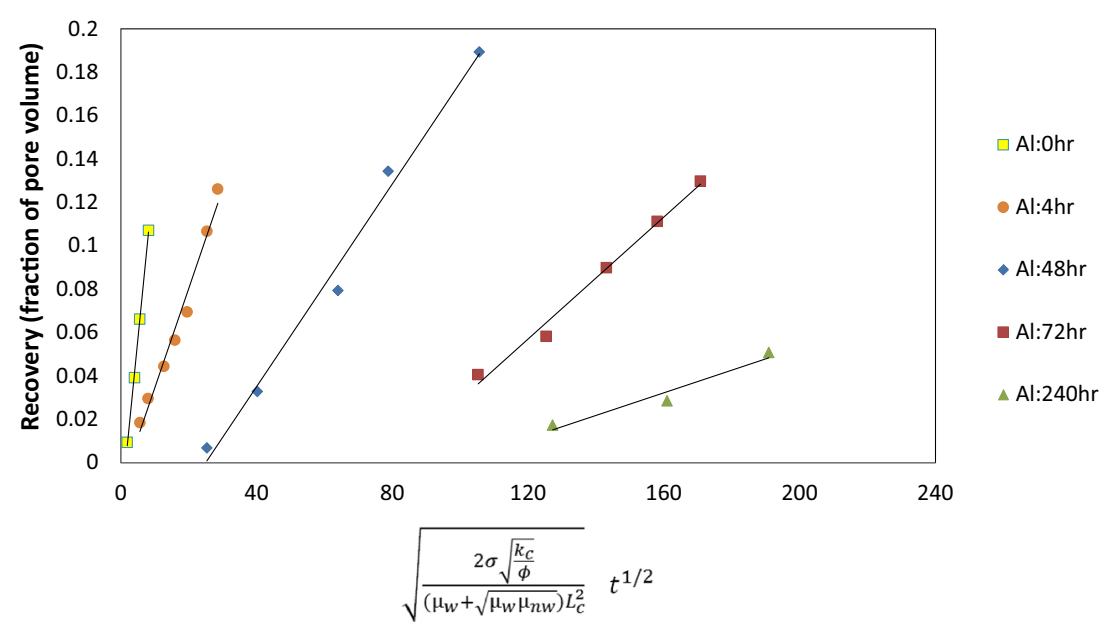

Regarding the above discussions, it should be emphasized that the experiments used in this section, either SWW or mixed-wet, have been conducted using Berea sandstone samples. Furthermore, the main finding of this section was supported by one set of SWW and three sets of mixed-wet experiments. There is not any more suitable set of experiments in the literature to be used in this section. Thus, the authors assume these four sets of experiments are enough to generalize the ability of the subject VSG to scale experiments.

\section{Comparison between the MPMS indices estimated by the proposed method with the original one}

In this section, it is intended to compare the MPMS indices estimated by the proposed method (i.e., by incorporation of 
Fig. 6 Curves of recovery normalized by pore volume versus $\sqrt{\frac{2 \sigma \sqrt{\frac{k_{\mathrm{c}}}{\phi}}}{\left(\mu_{\mathrm{w}}+\sqrt{\mu_{\mathrm{w}} \mu_{\mathrm{nw}}} L_{\mathrm{c}}^{2}\right.}} t^{1 / 2}$ for the second set of experiments performed by Zhou et al. (2000) (with initial water saturations close to $20 \%$ )

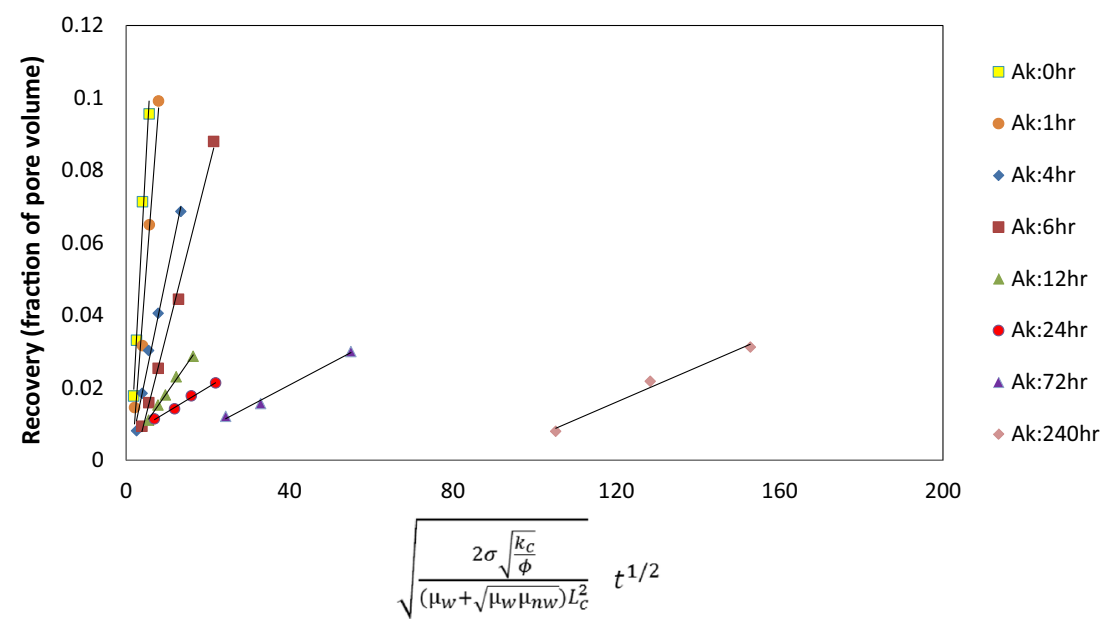

Fig. 7 Curves of recovery normalized by pore volume versus $\sqrt{\frac{2 \sigma \sqrt{\frac{k_{\mathrm{c}}}{\phi}}}{\left(\mu_{\mathrm{w}}+\sqrt{\left.\mu_{\mathrm{w}} \mu_{\mathrm{nw}}\right) L_{\mathrm{c}}}\right.}} t^{1 / 2}$ for the experiments performed by Viksund et al. (1998) on SWW samples with initial water saturations of 14.8 and $20.0 \%$

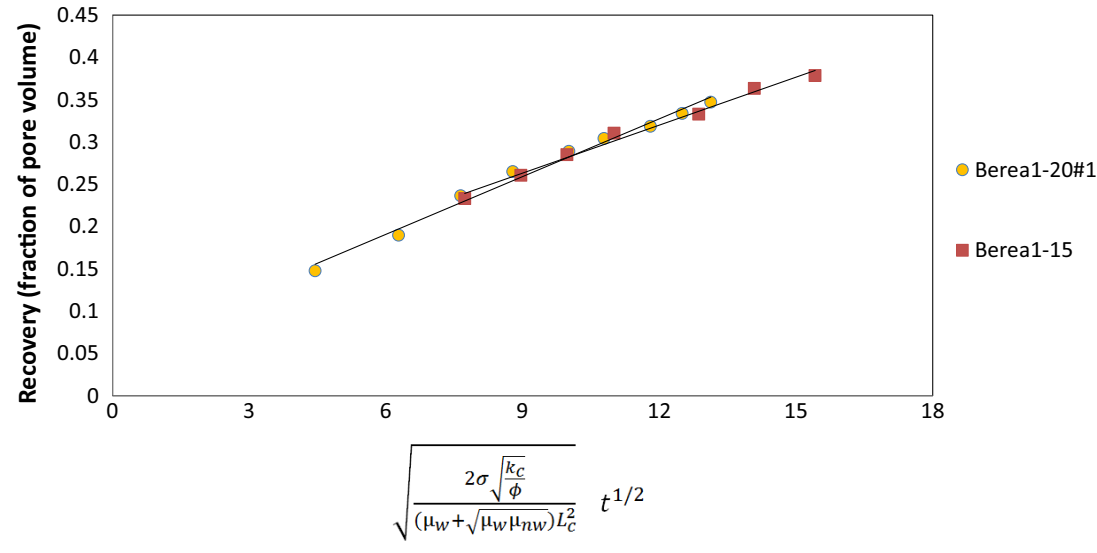

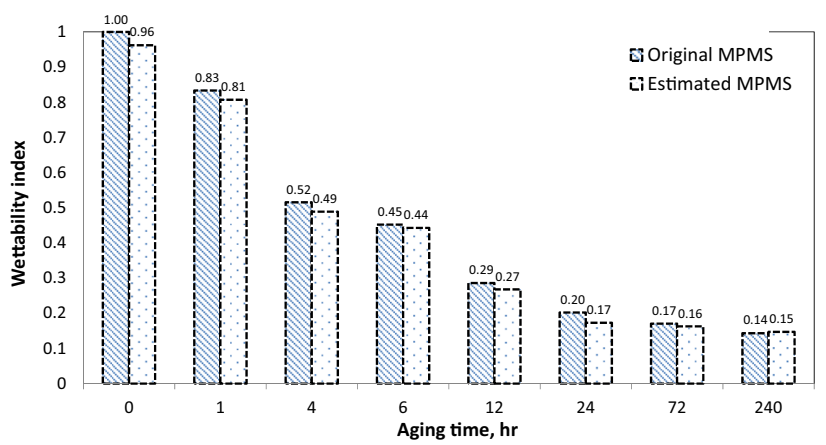

Fig. 9 Comparison of wettability indices to water $\left(Z_{\mathrm{w}}\right)$ by the original MPMS and the new technique versus aging time for the COUCSI tests performed by Zhou et al. (2000) with initial water saturations close to $20 \%$

These data were used by Mirzaei-Paiaman et al. (2013), as well. The relevant rock and fluid properties of their experiments are listed in Table 4. They aged the plug samples for different time periods to provide varying degrees of water wetness and performed the AFO COUCSI experiments with evacuated Alaskan crude oil and available sets are those presented by Zhou et al. (2000). 
synthetic formation brine as, respectively, the nonwetting and wetting phases. Their experiments can be classified into two series: (1) the tests Al:0 h to $\mathrm{Al}: 240 \mathrm{~h}$ with initial water saturations close to $15 \%$ and (2) the tests Ak:0 h to Ak:240 h with initial water saturations close to $20 \%$. Upon aging, wettability of the samples was altered from initial SWW to weakly water wet conditions. Therefore, with the exception of wettability/aging time, all parameters including initial water saturation, viscosity ratio, pore structure, and boundary condition are nearly identical for each set of the experiments.

To show the good performance of the proposed method, two reference experiments on SWW media with initial water saturation, pore structure, and boundary conditions the same as the restored-state experiments of Zhou et al. (2000) but with a different viscosity ratio are required. A complete survey among the literature works revealed that the only SWW COUCSI tests with such characteristics are those presented by Viksund et al. (1998) (Table 5). These two experiments were performed with brine and refined oil with a viscosity ratio $\left(\mu_{\mathrm{nw}} / \mu_{\mathrm{w}}\right)$ of 1.478 which is different from the viscosity ratio of 40.59 in the experiments of Zhou et al. (2000).

For all of the reported experiments, the curve of oil recovery normalized by pore volume is plotted against the group $\sqrt{\frac{2 \sigma \sqrt{\frac{k_{\mathrm{c}}}{\phi}}}{\left(\mu_{\mathrm{w}}+\sqrt{\mu_{\mathrm{w}} \mu_{\mathrm{nw}}}\right) L_{\mathrm{c}}^{2}}} t^{1 / 2}$ (Figs. 5, 6, 7) and the slope is computed from the straight portion of the resulting curve by linear regression. There may be some deviations from the expected linear trend, particularly at very early and late times (for the possible reasons see Mirzaei-Paiaman et al. 2013; Hamidpour et al. 2015; Mirzaei-Paiaman 2015). These deviations are excluded from the regression analysis. It should be noted here that the slope of the test Berea1-15 is considered as the reference value $\left(X_{\text {ref }}\right)$ for the tests $\mathrm{Al}: 0 \mathrm{~h}$ to $\mathrm{Al}: 240 \mathrm{~h}$ with initial water saturations close to $15 \%$, while for the tests Ak:0 h to Ak:240 h with initial water saturations close to $20 \%$ the reference slope is computed using regression analysis of the test Berea120\#1. The calculated values of $X$ and $X_{\text {ref }}$ with the corresponding correlation coefficients (i.e., $R^{2}$ ) are reported in Tables 4 and 5, respectively. The values of $X$ in Table 4 are divided by the corresponding value of $X_{\text {ref }}$ from Table 5 to estimate MPMS wettability index to water $\left(Z_{\mathrm{w}}\right)$ in accordance with Eq. 8. These values are reported in the last column of Table 4. A comparison between the original wettability indices by MPMS and the corresponding estimated indices by the proposed technique for the two sets of experiments was made in Figs. 8 and 9. Despite the viscosity ratio of the restored-state and reference systems are significantly different, the estimated indices are in a good agreement with the corresponding original indices.

\section{Conclusions}

The same viscosity ratio between the native- or restoredstate and reference systems is one of the most important restrictive conditions to the applicability of the MPMS method. The VSG $\mu_{\mathrm{w}}+\sqrt{\mu_{\mathrm{w}} \mu_{\mathrm{nw}}}$ gives rise to the very good scaling of COUCSI experimental data over several orders of magnitude variation of nonwetting to wetting phase viscosity ratio in the SWW and mixed-wet systems studied in this work. This VSG was used to rule out the viscosity ratio dependence of the terms $X$ and $X_{\text {ref }}$ during slope analysis of COUCSI recovery data. The estimated indices by the proposed method were in good agreement with actual MPMS indices.

Acknowledgments The authors would like to thank National Iranian South Oil Company (NISOC) and National Iranian Oil Company (NIOC) for permission to publish this paper.

Open Access This article is distributed under the terms of the Creative Commons Attribution 4.0 International License (http:// creativecommons.org/licenses/by/4.0/), which permits unrestricted use, distribution, and reproduction in any medium, provided you give appropriate credit to the original author(s) and the source, provide a link to the Creative Commons license, and indicate if changes were made.

\section{References}

Adamson AW (1982) Physical chemistry of surfaces, 4th edn. John Wiley and Sons Inc, New York

Amott E (1959) Observations relating to the wettability of porous rock. Trans AIME 216:156-162

Babadagli T (1996) Temperature effect on heavy-oil recovery by imbibition in fractured reservoirs. $J$ Pet Sci Eng 14(3-4):197-208

Behbahani HS, Blunt MJ (2005) Analysis of imbibition in mixed-wet rocks using pore-scale modeling. SPE J 10(4):466-474

Boneau DF, Clampitt RL (1977) A surfactant system for the oil-wet sandstone of the North Burbank Unit. J Pet Technol 29:501-506

Cuiec LE, Bourbiaux BJ, Kalaydjian F (1994) Oil recovery by imbibition in low-permeability chalk. J SPE Formation Eval 9(3):200-208

Denekas MO, Mattax CC, Davis GT (1959) Effects of crude oil components on rock wettability. J Pet Technol 11(11):330-333

Donaldson EC, Thomas RD, Lorenz PB (1969) Wettability determination and its effect on recovery efficiency. SPE J 9(1):13-20

Fischer H, Morrow NR (2006) Scaling of oil recovery by spontaneous imbibition for wide variation in aqueous phase viscosity with glycerol as the viscosifying agent. J Pet Sci Eng 52(1-4):35-53

Fischer H, Wo S, Morrow NR (2008) Modeling the effect of viscosity ratio on spontaneous imbibition. SPE Res Eval Eng 11(3):577-589

Fleury M, Deflandre F (2003) Quantitative evaluation of porous media wettability using NMR relaxometry. Magn Reson Imaging 21(3-4):385-387

Gupta A, Civan F (1994) An improved model for laboratory measurement of matrix to fracture transfer function parameters in immiscible displacement. Paper SPE 28929 presented at the

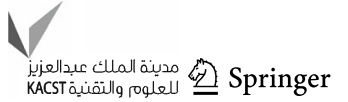


SPE Annual Technical Conference and Exhibition, New Orleans, Louisiana, USA, Sep 25-28

Hamidpour E, Mirzaei-Paiaman A, Masihi M et al (2015) Experimental study of some important factors on nonwetting phase recovery by cocurrent spontaneous imbibition. J Nat Gas Sci Eng 27(2): 1213-1228

Iffly R, Rousselet DC, Vermeulen JL (1972) Fundamental study of imbibition in fissured oil fields. Paper SPE 4102 presented at the SPE Annual Fall Meeting of AIME, San Antonio, Texas, Oct $8-11$

Leverett MC (1941) Capillary behavior in porous solids. Trans AIME 142:152-169

Longeron D, Hammervold WL, Skjaeveland SM (1995) Water-oil capillary pressure and wettability measurements using micropore membrane technique. Paper SPE 30006 presented at the International Meeting on Petroleum Engineering, Bejing, China, Nov $14-17$

Lucas R (1918) About the time law of the capillary rise of fluids. Kolloid-Zeitschrift 23:15-22

Ma S, Zhang X, Morrow NR (1995) Influence of fluid viscosity on mass transfer between rock matrix and fractures. Paper PETSOC-95-94 presented at the Annual Technical Meeting, Calgary, Alberta, Canada, June 7-9

Ma S, Morrow NR, Zhang X (1997) Generalized scaling of spontaneous imbibition data for strongly water-wet systems. J Pet Sci Eng 18(3-4):165-178

Ma S, Morrow NR, Zhou X et al (1999) Characterization of wettability from spontaneous imbibition measurements. J Can Pet Technol Special Edition 38(13):1-8

Mason G, Fischer H, Morrow NR et al (2010) Correlation for the effect of fluid viscosities on counter-current spontaneous imbibition. J Pet Sci Eng 72(1-2):195-205

Mattax CC, Kyte JR (1962) Imbibition oil recovery from fractured, water-drive reservoir. SPE J 2(2):177-184

McWhorter DB, Sunada DK (1990) Exact integral solutions for twophase flow. Water Resour Res 26(3):399-413

Mirzaei-Paiaman A (2015) Analysis of counter-current spontaneous imbibition in presence of resistive gravity forces: displacement characteristics and scaling. J Unconv Oil Gas Resourc 12:68-86

Mirzaei-Paiaman A, Masihi M (2013) Scaling equations for oil/gas recovery from fractured porous media by counter-current spontaneous imbibition: from development to application. Energy Fuels 27(8):4662-4676

Mirzaei-Paiaman A, Masihi M (2014) Scaling of recovery by cocurrent spontaneous imbibition in fractured petroleum reservoirs. Energy Technol 2(2):166-175

Mirzaei-Paiaman A, Masihi M, Standnes DC (2011a) An analytic solution for the frontal flow period in 1D counter-current spontaneous imbibition into fractured porous media including gravity and wettability effects. Trans Porous Media 89(1):49-62

Mirzaei-Paiaman A, Masihi M, Standnes DC (2011b) Study on nonequilibrium effects during spontaneous imbibition. Energy Fuels 25(7):3053-3059
Mirzaei-Paiaman A, Masihi M, Standnes DC (2013) Index for characterizing wettability of reservoir rocks based on spontaneous imbibition recovery data. Energy Fuels 27:7360-7368

Ruth D, Mason G, Morrow N et al (2004) The effect of fluid viscosities on countercurrent spontaneous imbibition. Paper SCA2004-11 presented at the Society of Core Analysts Symposium, Abu Dhabi, UAE, Oct 5-9

Saboorian-Jooybari H, Khademi N (2014) Traveling wave analysis of cocurrent imbibition in porous media. $\mathbf{J}$ Porous Media 17(3):185-195

Schmid KS, Geiger S (2012) Universal scaling of spontaneous imbibition for water-wet systems. Water Resour Res 48 (No. W03507)

Schmid KS, Geiger S (2013) Universal scaling of spontaneous imbibition for arbitrary petrophysical properties: water-wet and mixed-wet states and Handy's conjecture. J Pet Sci Eng 101:44-61

Schmid KS, Geiger S, Sorbie KS (2011) Semianalytical solutions for cocurrent and countercurrent imbibition and dispersion of solutes in immiscible two-phase flow. Water Resour Res 47(2) (No. W02550)

Sharma MM, Wunderlich RW (1985) The alteration of rock properties due to interactions with drilling fluid components. Paper SPE 14302 presented at the SPE Annual Technical Conference and Exhibition, Las Vegas, NV, Sept 22-26

Standnes DC (2009) Calculation of viscosity scaling groups for spontaneous imbibition of water using average diffusivity coefficients. Energy Fuels 23(4):2149-2156

Strand S, Standnes DC, Austad T (2006) New wettability test for chalk based on chromatographic separation of $\mathrm{SCN}^{-}$and $\mathrm{SO}_{4}{ }^{2-}$. J Pet Sci Eng 52:187-197

Tavassoli Z, Zimmerman RW, Blunt MJ (2005) Analytic analysis for oil recovery during counter-current imbibition in strongly waterwet systems. J Transp Porous Media 58(1):173-189

Tong ZX, Xie X, Morrow NR (2002) Scaling of viscosity ratio for oil recovery by imbibition from mixed-wet rocks. Petrophysics 43(4):338-346

Trantham JC, Clampitt RL (1977) Determination of oil saturation after waterflooding in an oil-wet reservoir-The North Burbank Unit, Tract 97 Project. J Pet Technol 29(5):491-500

Viksund BG, Morrow NR, Ma S et al (1998) Initial water saturation and oil recovery from chalk and sandstone by spontaneous imbibition. Paper SCA-9814 presented at the Society of Core Analysts International Symposium, The Hague, The Netherlands

Wang R (1999) gas recovery from porous media by spontaneous imbibition of liquid. MS Thesis, University of Wyoming, Laramie, Wyoming

Zhou X, Morrow NR, Ma S (2000) Interrelationship of wettability, initial water saturation, aging time, and oil recovery by spontaneous imbibition and waterflooding. SPE J 5(2):199-207 